\title{
Spatial Analysis of Rural Labor Transfer in China
}

\author{
Luan Qinglin
}

Beijing Jiaotong University, Beijing10044

\author{
Keywords: Labor, Transfer, Spatial Analysis
}

\begin{abstract}
Since the reform and opening, urbanization is the only way to modernization, and this has become the consensus. However, choosing what scale of the city can be taken as the spatial carrier of labor transfer, and this becomes a focus issue of scholarly debate. Among various views, the small cities and towns strategy, taking the small cities and towns as a priority development, has always been dominant in theory. What's more, in the practice the Chinese government also tends to give priority to develop the small cities and towns, and adopts the policy of "controlling the size of large cities and developing the medium-sized cities reasonably". We should examine China's rural labor transfer from the spatial dimension so as to demonstrate the fact that large and medium-sized cities are the efficient spatial carriers of China's rural labor transfer, and dismiss the urbanization strategy with popular elements of today's era that we should give priority to develop the small cities and towns.
\end{abstract}

\section{Introduction}

The small cities and towns have made an indelible contribution on the aspect that China transfers rural population to urban population. However, "the small cities and towns strategy" means that we should realize the transformation from agricultural civilization to industrial civilization based on the premise that try not to change the existing urban-rural dual pattern. Its essence is shown as follows. We do this all out of guaranteeing the welfare thought of urban residents and being lack of comprehensive and correct understanding of industrialization and urbanization so as to prevent "the urban disease". However, lack of the predictability of "rural disease", we only see the benefits of "leaving the farmland but not people's hometown, and entering the factory but not people's cities", but we can't see the harms which are brought by the fact of violating the universal law of urbanization. As far as the production technology and the workers' quality are concerned, the small cities and towns are far less higher than big and medium cities. However, for the advantages of flexible operation mechanism, the small cities and towns attract the inflow of production factors, and the cities reduce the appeal because of the slow system transformation. That is to say, the spatial flow and configuration of production factors caused by the rapid development of small cities and towns do not conform to the technical principle of optimal configuration. With the development of China's economy and the deepening of the system reform, the disadvantages of small cities and towns strategy have been displayed day by day. They can be described as follows.

Firstly, the development of small cities and towns is lack of scientific planning and rational layout, much quantity, wide area, and it can't display the urban functions. Because the number of small cities and towns grows too fast and many cities and towns are upgraded to cities, these make the scale and the infrastructure of small cities and towns, and the development level of tertiary industry be all relatively weak. Secondly, the infrastructure of small cities and towns is weak, and has the single function, and the extensive land use is all general. As is known to all, the primary characteristic of cities is intensive. The greater the city scale is, the higher the population density, the higher the population and the output density for unit land are also, and the more intensive the land utilization is naturally.

Thirdly, the small cities and towns strategy is extremely bad for us to reduce the environmental pollution in our country, prevent the further loss of water and soil, control the sandstorm phenomenon, maintain the ecological environment and others. 
Finally, the small cities and towns have encountered the unprecedented challenges in the aspect for the capacity of transferring the rural population.

After the overheating of China's economy has achieved a soft landing, the external conditions of sustaining economic growth have changed, in addition, the environment and resource destruction have been strictly limited, these make the extensive expansion advantages of township and village enterprises be no longer in existence, and the ability of absorbing rural surplus labor be far lower than expected level. Therefore, we have to examine the small cities and towns strategy again and have the deep thoughts on the road of urbanization in our country.

\section{The Opposite Direction between Small Cities and Towns Strategy and Urbanization Goal}

The ultimate goal of urbanization is mainly shown as follows. Firstly, by urbanization we can realize the transfer of rural labor to make the population distribution structure change. That is to say, we make the population structure change from the agriculture-based population and the rural-based population to the non-agriculture-based population and the urban-based population. Secondly, through such a dynamic change of urbanization, geographically, a more orderly and perfect town classification system which is combined comprehensively by population, productive forces and other many factors is formed. This system is the important achievement of social evolution, and it is also the support for the development of social productive forces. This system will become the skeleton of the national economic growth and social development in the future. In the author's opinion, these two goals aren't at the same level, and the ultimate goal of urbanization can change the population distribution structure, and make everyone can enjoy the benefits brought by the modernization in the city. What's more, an orderly and perfect town classification system is the means of achieving this goal, and it also the insurmountable stage of achieving this goal. If we ignore this stage, and we only emphasize the changes in the structure of population distribution, we will "spoil things by excessive enthusiasm" and "haste makes waste". The defect of small towns strategy ultimately exists in the emphasis on the change of population distribution structure too much. Although the following situation is in its consideration, the special situation of China's large population can attract hundreds of millions of rural population, but it cannot rely on one hundred big cities whose current populations more than one million, in fact, it doesn't consider that the transfer of population needs the support of the economy, and it also doesn't consider that the whole society will pay for the price which the population moves to small towns.

\section{Positive Development of Big Cities----the Best Strategic Choice of Promoting Urbanization in China at Present}

\subsection{Experience Basis}

According to the international experience, taking big cities and megalopolises as a growth priority is the general trend and the general law of the world urbanization development among various countries in the world. The history of world urbanization shows that the urbanization is the development of a few cities alone at first, and after reaching a certain scale the follow-up rapid development of a large number of small cities and towns appears. Europe, America and Japan and other countries all have given full play to the special function of big cities in the process of industrialization. In the aspects of capital accumulation, population agglomeration, scale effect, radiation impetus effect and high economic and sustainable growth they have played an immeasurable role in the economies of these developed countries. And in this way, megalopolises, such as London, Tokyo, Seoul, Taipei and other countries, with over 1/10 of the total population in the country (or region) have formed.

\subsection{Theoretical Basis}

Agglomeration economy principle is a classic thoughts in urban and regional economic theories. The German, A Weber, first suggested to strengthen the analysis research on economic agglutination function. In his opinion, the agglomeration can make the enterprises obtain the agglomeration 
economy of cost savings. His definition of agglomeration economy is shown as follows. Agglomeration economy is produced like this. People make the production proceed by agglomerating things in the same place according to a certain scale, therefore, it brings the benefits or causes the savings for the aspects of production or sale. Obviously, due to intensive enterprises, good infrastructure, convenient transportation, and advanced finance, insurance, information consulting and other industries in big cities, the enterprises in big cities are more likely to obtain the agglomeration economy than the enterprises in small cities and towns, and the enterprises in big cities are more likely to bring the savings and benefits for the productions or sales of enterprises.

\subsection{Nation State Basis}

Firstly, positive development of big cities is the request of personal average resources shortage in our country. Urbanization means the all-round improvement of people's living standard and the increasing consumption of resources. As far our country with very personal average resources shortage is concerned, this is a question of dilemma. In order to break through this dilemma, the urbanization of our country must take the path of considering the benefits as central point. Based on the experience of the country whose world has been urbanized, the benefits of big cities are higher than the benefits of small cities and towns.

Secondly, positive development of big cities is the request of China's large population. China has large population, and people concentrate in big cities. In fact, compared with the situation that people scatter in many small cities and towns, it is more conducive to the development of the whole economy and society. The reason for that is explained as follows. Compared with population scatter settlements, population concentration settlements is more conducive to protect the ecological environment. Population concentration settlements is conducive to population size control and population quality improvement. Population concentration settlements is conducive to the development of the tertiary industry, and it is conducive to solve the problem of unemployment. Population concentration settlements is conducive to give full play to the city's economic agglomeration effect, size effect and size overflow effect, and it is also conducive to the rapid development and the sustainable development of economy.

Thirdly, positive development of big cities is the request of hundreds of millions of farmers' urgent pursuit for city civilization in China. The essence of urbanization is the process that the rural population transfers to the cities, and it is also the process that farmers pursue and demand to share the urban civilization. Urbanization in our country must seriously consider to meet the wishes, demands and intentions that hundreds of millions of farmers transfer to the cities. Seen from the perspective of farmers, although small cities and towns in our country absorb a large number of farmers to make them become urban residents, due to small size and single function, no matter in infrastructures, public services or residents' living habits, these administrative towns are closer to the countries rather than the cities. Therefore, it cannot satisfy the farmers' desires for the civilization of big cities. For this kind of desire, Wang Qiong who comes from School of Economics, Beijing Normal University had the poignant argument, "We found that the farmers who went to big cities even bit the teeth to keep paying for the temporary residence fee, administrative fee, physical examination fee, migrant work fee and high-price house rent, enduring the contemptuous look, the abuses, the expelling, the extreme cold and hot weather, and risking all kinds of hazards for having illness but having no money to see the doctor, having industrial injury but having no labour insurance, and having been defrauded, punished and repatriated, they still would rather choose distant big cities, and they rarely enjoy the convenience of moving to small cities and the family affection of 'often going home to see the family members'”.

\section{Conclusion}

In conclusion, we should change the strategy of small cities and towns with development priority into the strategy of big cities with development priority. Emphasizing big cities with development priority doesn't stand for stopping developing small cities and towns. About the development of small cities and towns we should not emphasize an increase in quantity again, but we should 
emphasize the improvement in quality. About small cities and towns we should emphasize removal and merger so as to concentrate them in cities and counties, and central towns. In this way, it is conducive to bring the city function into play, have the land conservation. Thus, it is better promote the development of economy, and reduce the farmers' cost of entering into the cities.

The key of developing big cities is how to solve the problem of urban illness. The population of Tokyo settlement is more than 30 million, and Tokyo is the largest population settlement in the world. However, because Tokyo has very high city management level, instead, it not only doesn't have the problem of urban illness but also creates the highest productivity and the highest efficiency in the world. The per capita gross domestic product in Tokyo locates at the highest level in the world. All of the output in Tokyo is almost the same with China's national output. On the contrary, in some countries, the city size is relatively small, the population is only two hundred thousand and three hundred thousand. However, due to its limited management function, the city seems to be too big so that a series of urban problems appear. Thus, it can be seen that "city illness" is not necessarily associated with urban size. The key to solve "city illness" is to do the city management well rather than blindly do emphasis on the city size control.

\section{References}

[1] Li Jingjing, Miao Changhong. Influence ofPopulation Flow in the Yangtze River Economic Belt on the Regional Economic Differences [J]. Geography Journal, 2017, (02):197-212.

[2] Chi Shangxin, Chen Cheng. Backside Effect: Population Mobility and Urban and Rural Residents’ Political Attitude [J]. China Rural Survey, 2016, (05):22-36+94-95.

[3] He Xin.Research on Real Estate Prices Spatial Diversity under the Perspective of Population Flow [D]. Xiangtan University, 2016.

[4] Cheng Jianxin, Liu Junqiang and Wang Jun. Differences among Population Mobility, Residential Model and Interregional Crime Rate [J]. Sociological Research, 2016, (03):218-241+246. 